\title{
Engineering of a Student Advisory Management System: Development Perspective
}

\author{
Ikono Rhoda Nsikan-Abasi, Gambo Ishaya Peni, Adebayo Moses Olajuwon
}

Computer Science \& Engineering Department, Obafemi Awolowo University, Ile-Ife, Nigeria

\section{Email address:}

rhodo@oauife.edu.ng (I. R. Nsikan-Abasi), ipgambo@oauife.edu.ng (G. I. Peni), olajuwon2all@yahoo.com (A. M. Olajuwon)

\section{To cite this article:}

Ikono Rhoda Nsikan-Abasi, Gambo Ishaya Peni, Adebayo Moses Olajuwon. Engineering of a Student Advisory Management System: Development Perspective. American Journal of Software Engineering and Applications. Vol. 5, No. 4, 2016, pp. 21-32.

doi: $10.11648 /$ j.ajsea.20160504.11

Received: August 3, 2016; Accepted: November 25, 2016; Published: January 9, 2017

\begin{abstract}
Web presence is gradually becoming an essential part of every learning institute. This is why a large portion of academic activities is becoming available online. However, despite the emerging growth in the use of information technology towards academics, it is still a challenge for part advisers to effectively monitor and mentor their students' academic activities, progress and processes. This paper attempts to justify the need to bridge the gap between students and their advisers through the use of web based technology. The paper adopted the qualitative research approach and a face-to-face interview with 24 Part Advisers from seven (7) faculties of the Obafemi Awolowo University, Nigeria. 120 students randomly selected from each faculty were also interviewed to know what their challenges and expectations are for such a system. Software development life cycle phases were strictly followed in the development process, and the Students Advisory Management System (SAMS) was implemented using web technologies. The system helps students stay up-to-date on their academic career by improving their level of communication with their assigned part advisers. It also helps part advisers better manage their students. The paper showed an enhancement to the SAMS from the development perspective. This will help overcome the various challenges encountered by different categories of learners in the learning process. Thus, the paper justified the need for knowledge suitable for learners, and provides advisers an automated platform for active interaction. The paper concludes that it is essential, therefore, that student' advisers understand the learning process and know how to facilitate its application throughout their areas of responsibility in an academic system, while giving the students the opportunity to receive better monitoring and mentoring in the course of their academics.
\end{abstract}

Keywords: Information Communication Technology, Student Advisory System, Web Technologies, Learning, Part Advisers, Students

\section{Introduction}

Education in all parts of the world has become the major facilitator to the ever increasing knowledge engendering quality development of both humans and systems. For example, education provides the most impactful environment for learning, innovation, and in building human capital required for a potential future knowledge economy. As seen in the last decade of technology age, a shift in awareness of the role of information technology (IT) is apparent even in the educational system. A clear example is the remarkable shift in the structure of the enabling information and communication technology (ICT) environment and the utilization of ICT technologies in education, most especially in the mentoring and monitoring process of students' activities, performance and productivity. This justifies the global reforms in education that ICT has engendered. Within the premise of ICT utilization for quality learning and effective monitoring of students' in the learning process, there is need to consider the development of a system that will further enhance the process. A typical example to justify the need this system is based on the the ratio of advisers to students in the Department of Computer Science and Engineering at the Obafemi Awolowo University, Ile-Ife, Nigeria. The current ratio of advisers to student is $2: 150$. This poses a threat on the effective management of the student's academic processes. As such, the students are left with minimal or no mentoring/monitoring which results to poor 
decisions taken by students pertaining to their career.

The study of learning processes, both cognitive and affective, allows researchers to understand individual differences in behaviour, personality, intellect, and selfconcept [1]. A better advisory system relies on conceptualizing new strategies for learning process and enhancing the academic performance of students. This system is technology driven, and requires that learning process through teaching, mentoring and monitoring be enhanced. It is believed that through teachers' use of technology, students can be given the opportunities of becoming a part of the knowledge age and skills imparted to the young people. Technology can be employed to the effective management of the students. When this happens, a conducive platform will be ensured in the assessment and evaluation of students academic performance.

\subsection{Learning as a Process}

Learning is seen as a process which undergoes three different interlocking factors for effectiveness [2]. These processes are as depicted in Figure 1, indicating the factors of the learning processes as: focus, environment and technique.

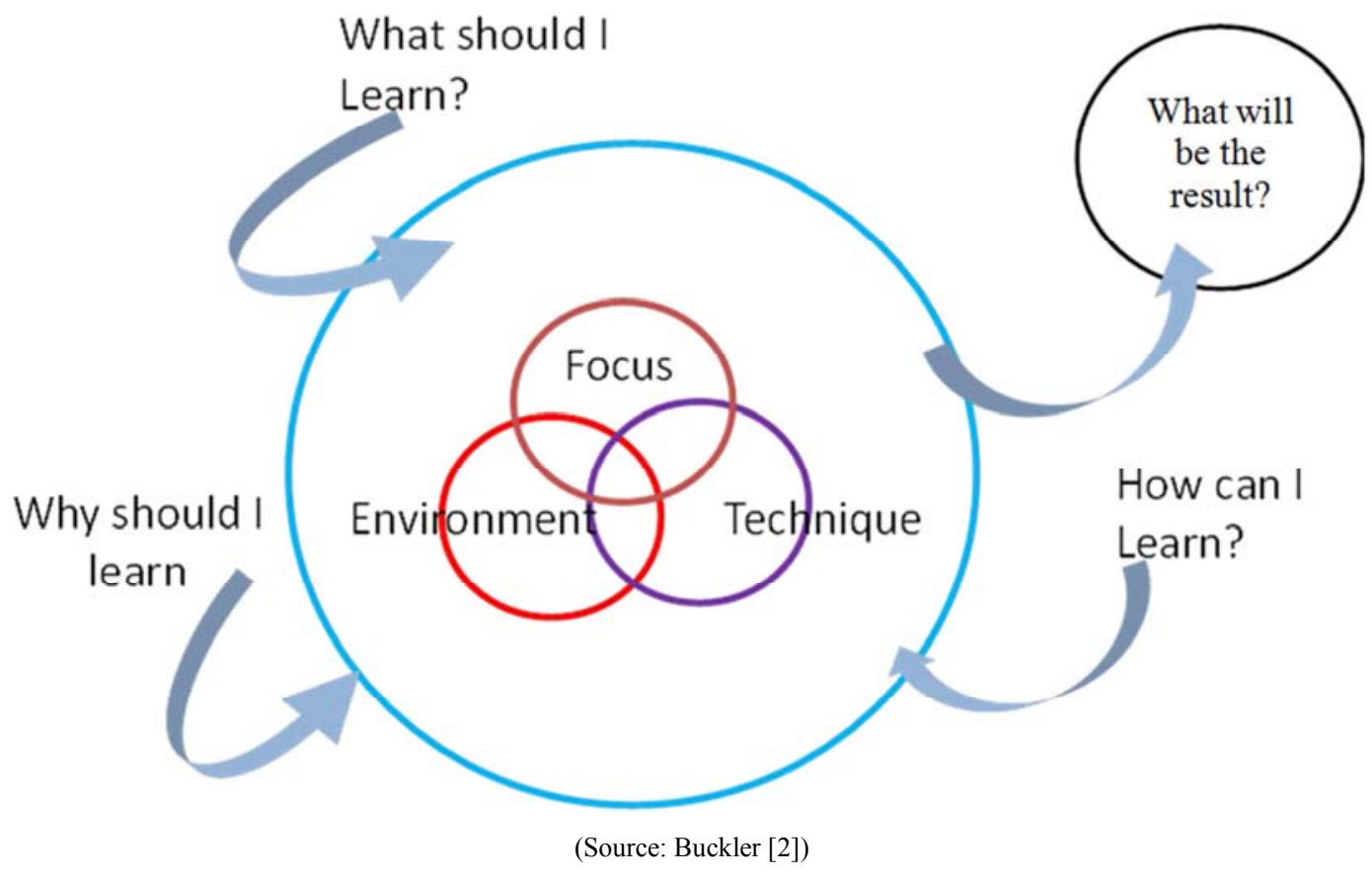

Figure 1. Learning Process Model.

Focus: Every learning process is usually defined so as to outline what will be learnt within the context of the process. Learning processes are directed towards a particular domain of knowledge which constitutes the focus parameter of the learning process $[3,4]$.

Environment: The environment facilitates learning and acts as the determining factor of the type of learning that can be derived therein. Hence, environment in learning processes provides the platform for the acquisition of knowledge $[5,6]$.

Technique: The efficiency of learning is determined by the method employed for learning to take place. There are various approaches towards learning. It ranges from the tradition class room teaching to the era of e-learning that now makes real-time video lecture possible. Technique in this context is the most crucial factor that needs to be work upon to further improve the learning process. The other factors which are focus and environment are readily available, but the main challenge is how to effectively transfer this knowledge (focus) through various possible environments that already exist. Thus, students' advisers have a major role to play in enhancing the technique ( $\mathrm{s}$ ) being employed in the learning environment.

\subsection{Learning Styles}

In the educational system, it is obvious that in an ideal class, students possess different learning ability. The rate or mode of assimilation is dependent on the students. These differences are an important factor that must be considered by students' advisers in performing their responsibilities. McLeod [7] opined that four different kinds of abilities necessitate the emergence of effective learning, which every students' adviser need to consider. The abilities includes: concrete experience (CE), reflective observation (RO), abstract conceptualization (AC), and active experimentation (AE). All these when put in place can engender quality learning style (s).

Effective learning in this context is determined when a person progresses through a cycle of the four stages. As such, learning is an integrated process where each stage can be mutually supportive of the other, and provides suitable feedbacks for continuity. It is possible to enter the cycle at any stage and follow it through its logical sequence [8]. However, effective learning only occurs when a learner is 
able to execute all four stages of the model. Therefore, no one stage of the cycle is as effective as a learning procedure on its own [9].

In Nigeria for example, managing students behaviour continues to be a high priority. This we believe is the case everyone in the world. In a national survey conducted recently, it was discovered that indiscipline is the most significant problem in schools (at all levels). This has been confirmed also through observation of successful teachers, and the impression that effective communication is what really determine good teaching skills. In [10], effective communication is said to be based on relationships, which is the key to success in learning.

\section{Methodology}

The typical stages of a system development life cycle was followed in the development process. These phases includes: planning, analysis, design, implementation and evaluation. In between the planning and analysis stages, requirements gathering and analysis were carried out to determine the key and targeted stakeholders', how the system will be used, the data that will be entered into the system, and the likely corresponding output from the system. A model was designed from the requirement specifications using the Unified Modelling Language. In particular, use case diagram was used. The system was implemented using web technologies, while alpha and beta testing were carried out in testing the system.

\subsection{Data Collection}

During the course of data collection, face-to-face interviews (structured and unstructured methods) was carried out. In particular, 24 Part Advisers (i.e. academic staff or course advisers) from seven (7) Faculties of the Obafemi Awolowo University, Nigeria were used as respondents. 120 students randomly selected from each Faculty were also interviewed to know what their challenges and expectations are for such a system. Also, in the course of data collection, various materials such as journals, research papers were gathered and reviewed. Related projects were studied so as to know the approaches used during implementation, and also to know the extent of work done in order to suggest and provide areas of improvement.

For example, the Benchmarking Learning Systems (BLS) used to assess student performance within the international context was studied. This system was developed with support from the Ford Foundation and the Nellie Mae Education Foundation by Darling-Hammond and Wentworth [11]. It was found that the system closely aligned with curriculum expectations, subject and performance criteria, and desired learning outcomes. The authors engage teachers in assessment development and scoring as a way to improve their professional practice and their capacity to support student learning and achievement. The system was used to engage students in authentic assessments to improve their motivation and learning. However, there is need to advance student learning in higher-order thinking skills and problem-solving by using a wider range of instructional and assessment strategies.

Other related systems include the student management system Run-min [12] and the Academic Decision-Support Based on Academic Performance Evaluation for Student and Program Assessment by Deniz and Ersan [13]. Also, the Sys Interface Inc. In Notley [14] provided a platform for students, lecturers and parents to collaborate on the learning activities of the students. This system justified the need for an efficient student management system with the provision of a Schools EdNet web enabled application in ASP. Net and powerful SQL server back end.

In [12], the following features were provided: manage courses within a class environment, support for profile based management: administrator, teacher and student, online teacher and student registration, allow students to selfmanage class enrolment allow teachers to manage student attendance and ability for students to submit course evaluations. The system focuses on the ability of students to manage their academic activities with no much focus on the effective management and mentoring of the students in their field of study.

On the other hand, Deniz and Ersan [13] showed that statistics plays an important role in assessment and evaluation of performance in academic environments. With our proposed system, the different ways in which student performance data can be analyzed and presented for academic decision-making. The aim is to provide a decisionsupport platform for academic administrators such that, data can be made available through the use of standard user interfaces, displays and graphs, as well as in tabular form.

\subsection{Design Specification}

The Unified Modelling Language (UML) tool was used to specify the structure and behaviour of the system. In particular, the use case diagram was used to describe the functionality provided by the system in terms of actors, their roles represented and the interaction that occur with other actors.

The use case diagram in Figure 2 describes all the actors (student and adviser) with their major interactions depicting the functionality of the system. The function of each use cases are described as follows:

i. Student: Is a class of person that acts as a student.

ii. Adviser: Is a class of person that acts as an adviser to the student.

iii. Update: It includes all the actions necessary for the adviser to respond to conversations from student and also to update the system.

iv. Performance analysis: Identify the $\log$ in student academic performance from their academic records.

v. Generate report: Uses the result of the performance analysis to generate report for the student.

vi. Retrieve: It includes all the actions necessary for the student to get information pertaining their academic process.

vii. Contact: it includes all the actions necessary for the student to invoke conversation with their adviser. 


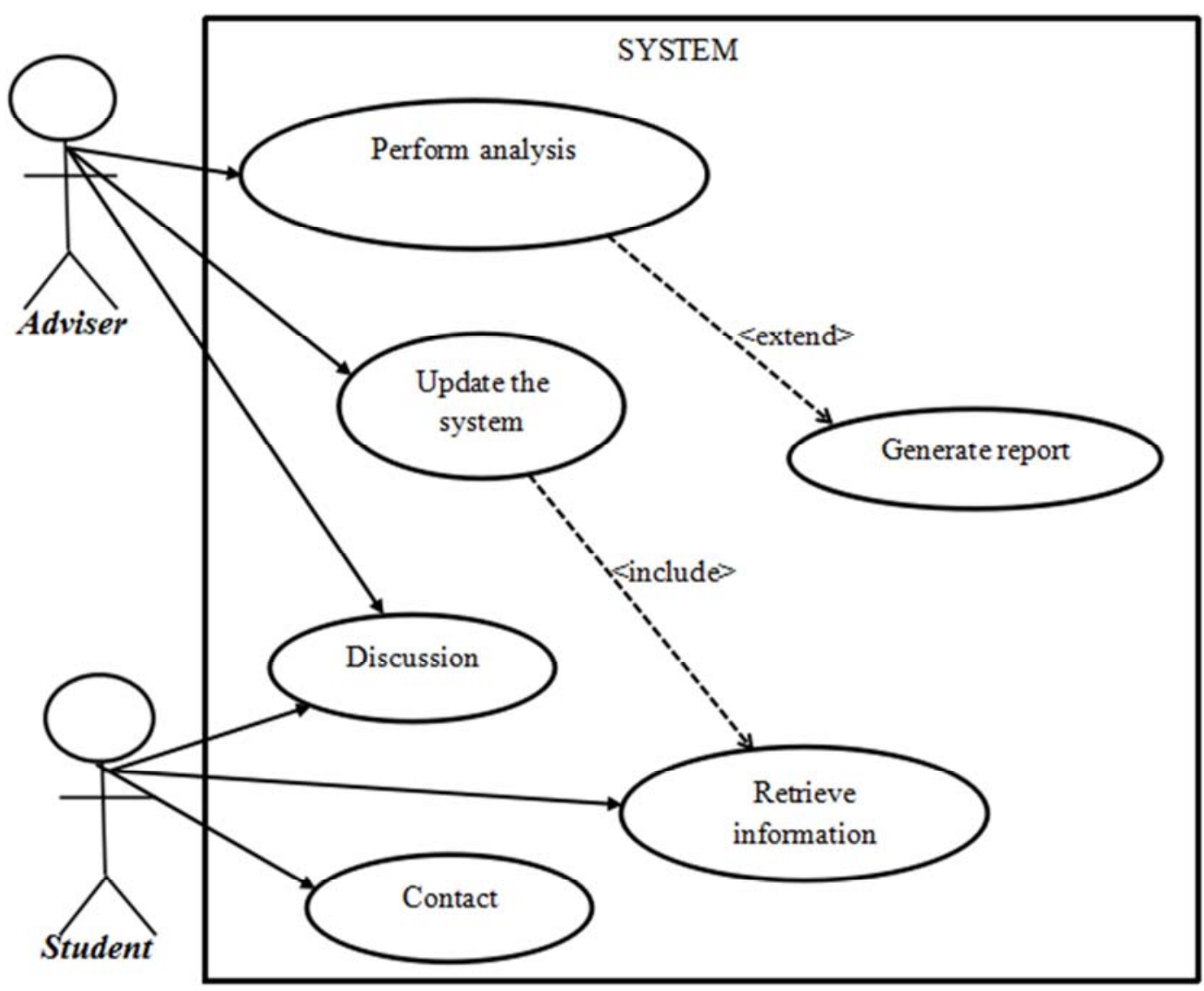

Figure 2. Use case diagram of student advisory system.

\subsection{System Architecture}

The overview of the system architecture is as shown in Figure 3. The flow of process of the student advisory management system is the system in perspective.

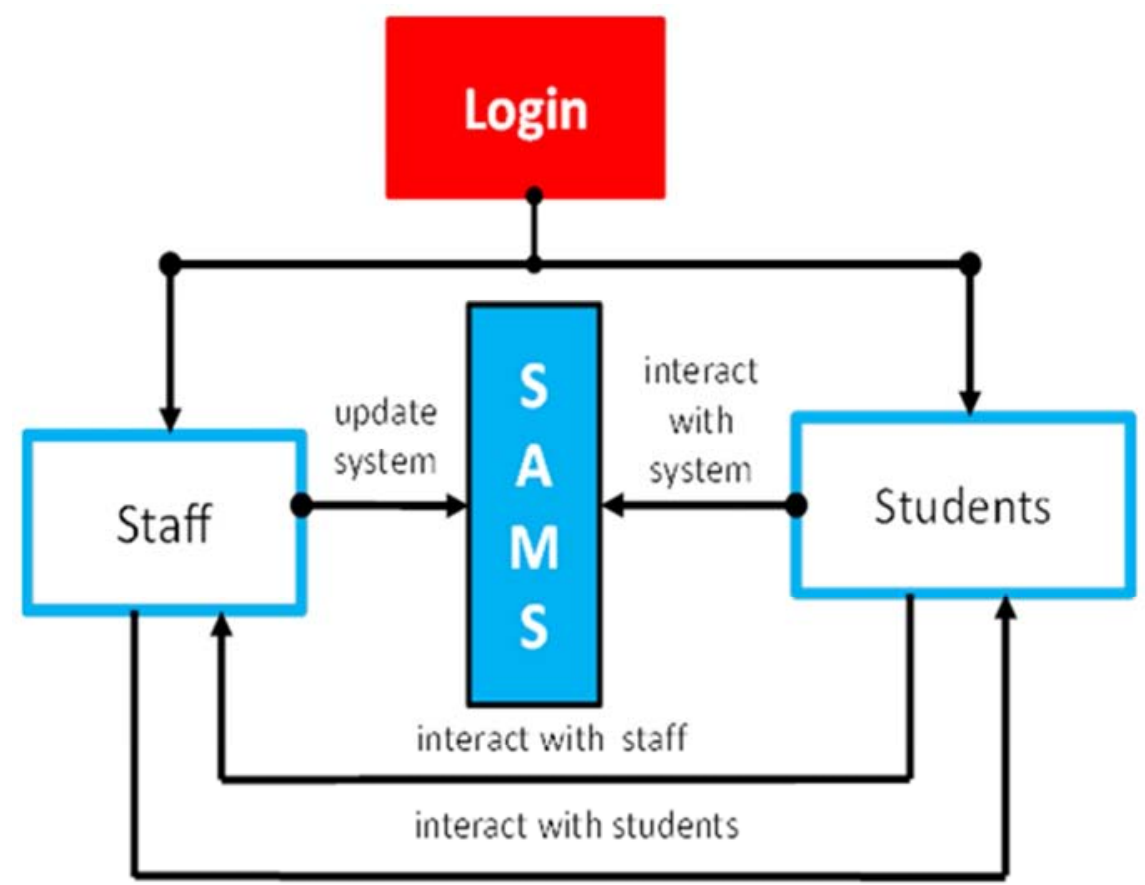

Figure 3. Architecture of the management system. 


\section{Implementation}

The implementation of the system was broken down into various components. These components are as follows:

a. User interface Structuring

b. Server-side Coding

c. Database

d. Data access layer

e. Web portal

All of these components are mainly used for software implementation.

\subsection{User Interface Structuring}

The User Interface (UI) is an essential component of the system that provides access for interaction. In the development process, the system was structured using Hypertext Markup Language (HTML), Cascading Style Sheet (CSS), and the client-side scripting was done with Javascript. The contents of the webpages were structured by denoting structural semantics for text such as headings, paragraphs, lists, links and other items used in the web pages. Also, HTML5 syntax was used to take advantage of the new features added to HTML, which addresses web applications. CSS was used to enable the separation of document contents from document presentation. This separation can improve content accessibility, provide more flexibility and control in the specification of presentation characteristics, enable multiple pages to share formatting, and reduce complexity and repetition in the structural content. Furthermore, CSS was used to allow the webpage display differently depending on the screen size or device on which it is being viewed.

JavaScript was used to implement the client-side scripts that interact with the user, control the browser, communicate asynchronously, and alter the document content displayed. JavaScript typically relies on a run-time environment (e.g. web browser) to provide objects and methods by which scripts can interact with the environment (e.g. a webpage DOM).

\subsection{Server-Side Coding}

Hypertext preprocessor (PHP) is the server-side scripting language used for the implementation of the server end of the project. PHP was used to send data to the database and to retrieve data from the database. PHP server was the connecting medium used to explore the database. Also, PHP was employed for the implementation of some part of the interface. This was used in the case where it might not be possible to use HTML or might be strenuous to use HTML. Also, object oriented PHP was used to allow a high level of code reuse for rapid development.

Furthermore, Asynchronous JavaScript and XML (AJAX) was used in loading new page content and submitting data to the server without reloading the page. With AJAX, data was sent and retrieved from a server asynchronously (in the background) without interfering with the display and behaviour of the existing page. The full page reload was avoided by creating XMLHttp Request object which have access to methods for exchanging data asynchronously between browser and server.

\subsection{Database}

The database was designed using MYSQL (My Structured Query Language) which is an open source relational database management system. The use of the database requires a server. The WAMP server been an acronym for "Windows, Apache, and MySQL" was used. MySQL is one of the central components used in the WAMP to administer data contained in the database. The structure of the staff and students' database is as depicted in figure 4 and 5 respectively.

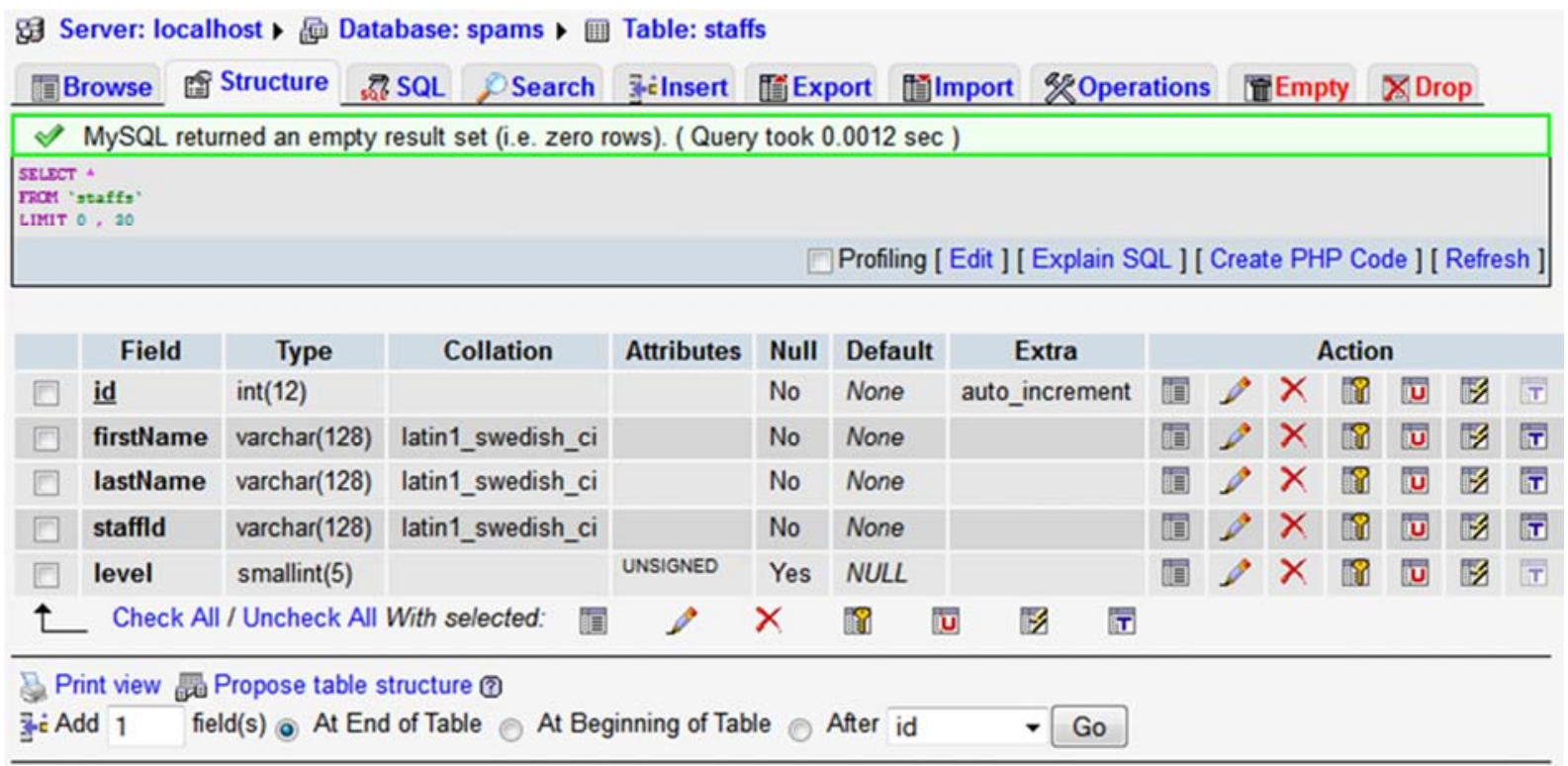

Figure 4. Structure for staff data. 


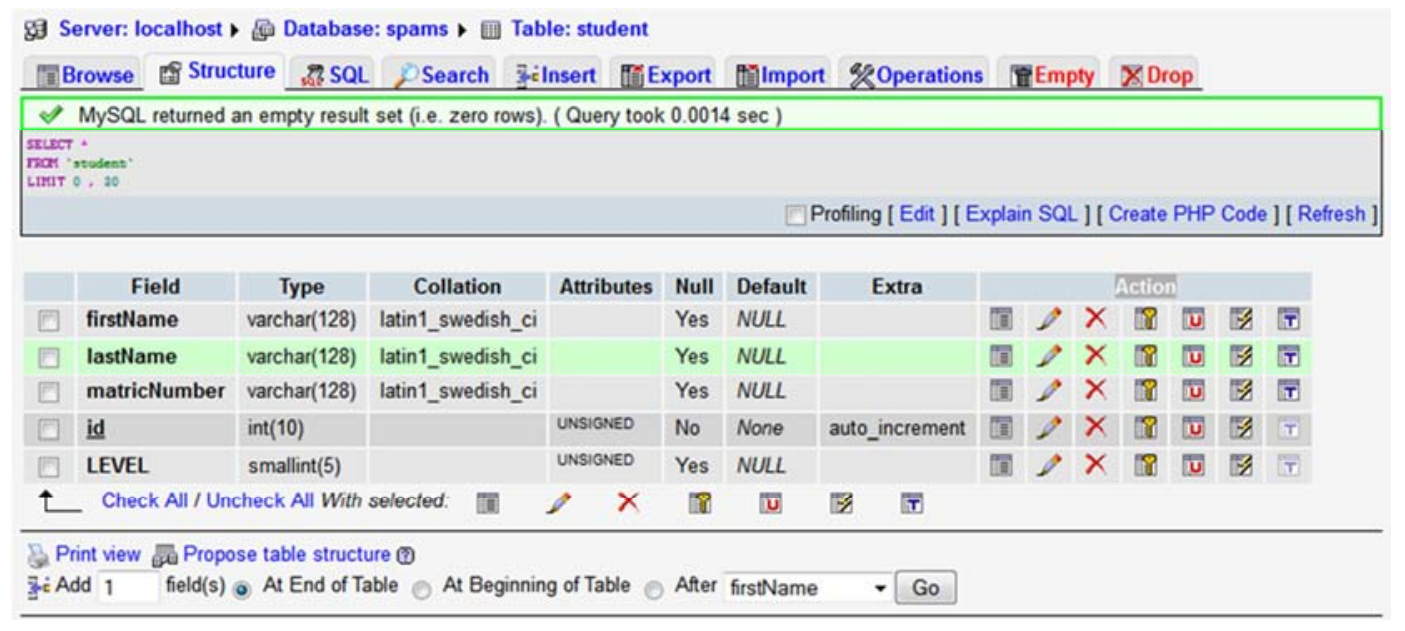

Figure 5. Structure for student data.

\subsection{Data Access Layer}

This layer was implemented using PHP files that contained classes that handle the creation, deletion, and manipulation of data in the database. These classes contained methods that the needed Structured Query Language (SQL) queries such as insertion, selection, and updating queries. These classes form a layer of abstraction by wrapping these SQL queries with methods that can be used in higher layers in the web page architecture. However, there are other PHP files which contained the code that aids the operation of these classes. These include the configuration files containing the database credentials, system global constants and so on.

\subsection{Web Portal}

The system consists of three main pages. These includes the login page, the students' page and the staffs' page. The login page was used to authenticate the user entering the web portal, and also direct them to their respective page depending on the type of user (either a student or a staff). The essence of this is to block non-authorized access to the portal. Again, new users (either staffs or students) can be made to register their login details on the login page. In the case of a student, the database checks for the records to determine whether such (records) exists. In the case where the record exist, the registration will be allowed, otherwise he/she will be alerted of the corresponding error that occur. Also, in the case of staffs, the record of the staff will be searched for in the database through the use of the staff id. If the record is found, the assigned level for the staff will be retrieved and also save as part of the log in details of the staff.

The students' page consists of the activities of the students and the related information posted by their part advisers. The students can send personal messages to their part adviser, check their results, view examinations and tests schedule, view information pertaining to their class, partake in the class discussions, fill the feedback forms, calculate their grade point average (GPA) and other related academic activities.

The staff login page is for staff that login and are given a level of privilege that is higher than the students. The staff are given an administrative privilege over the class they are assigned to. The staff can send personal message to their students, upload students' results, create examinations and tests schedule, create feedback forms and also retrieve academic performance report from the system.

\section{Discussion}

The scope of the Advisory System was limited to three levels (i.e. 3 classes, e.g level 1, 2 and 3) of a Department as a case study. The valid Matric numbers are between CSC/2008/XXX to CSC/2010/XXX. Two staff are assigned to each level as their part adviser. The part advisers for each level can use the advisory system to interact with their students. The system is flexible in such a way that the two advisers can jointly address the challenges faced by their students. The in-box of each adviser consists of messages labelled with either of these flags "Replied" or "No reply". Messages with the "Replied" tag at the bottom shows that they have been attended to by either the current login part adviser or the other part adviser. However, the part adviser can decide to initiate a new conversation with the student. Also, messages with "No Reply" showed that none of the part advisers have attended to it.

Thus, there is no need for the needless waiting of students and plans of meeting their part advisers in office when the need arise. The system serves as a medium for students to communicate their academic progress and situation to their part adviser and vice versa. Furthermore, the part advisers are notified of the pending message at the convenient time that they $\log$ into the system. The mode of interaction provided by the system will reduce the number of untreated issues faced by students.

\subsection{Feedback Response}

This system also serves as tool for part advisers to easily set-up feedback forms for their classes. The part advisers can use this feature to monitor and the identify factors affecting the academic performance of the students.

A heuristic algorithm was proposed for dynamic 
calculation of the mean response [15]. The estimate is produced dynamically as the students submit their response. The responses are not stored; therefore, the algorithm has a very small and fixed storage requirement regardless of the number of responses. This makes it ideal for the system to be open to a large extent in a university with larger population.

The algorithm is further extended to bar chart-plotting. The mean response calculated from the algorithm determines the height of each question in the bar chart. The system calculates the mean response for each question. The questions are meant to be close ended with five options: Strongly agree, partially agree, agree, disagree, and strongly disagree. The calculated mean gotten from the algorithm is depicted using the resultant integer value: $5,4,3,2, \& 1$. These values represents the mean response to the question either as strongly agree, partially agree, agree, disagree, and strongly disagree, respectively.
Going further, Figures 6, 7, 8, and 9 showed the login page of the system, users login panel, new student registration pop up and new Adviser registration pop up, respectively. Figure 10 and 11 presents the user interfaces for the students and staff respectively. In Figure 12, the data visualization of feedbacks is shown.

The data visualization aspect provides an environment for part advisers to easily set-up feedback forms for their classes. This feedback forms can be use to replace the traditional questionnaire. As shown in figure 12, the bar chart compared the mean response for each question in the questionnaire. The questions are meant to be close ended with five aforementioned options of Strongly agree, partially agree, agree, disagree, and strongly disagree. The mean answer is computed from the overall selection by the students' who partake in it. Each bar chart shows the mean answer selected by the users.
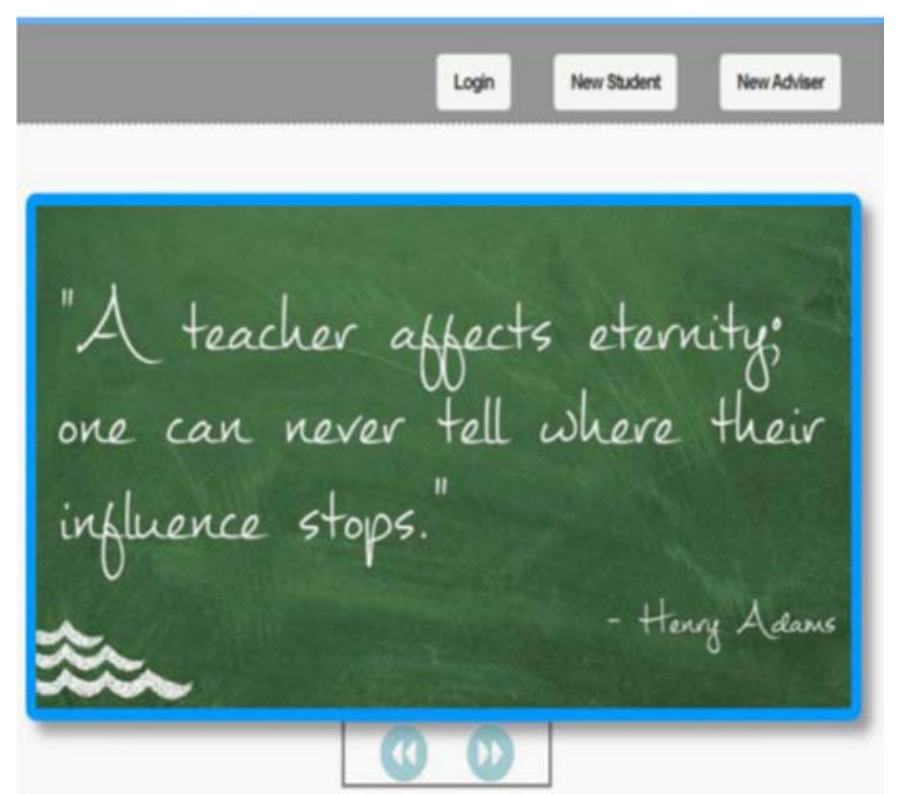

Figure 6. Login page of SAMS.

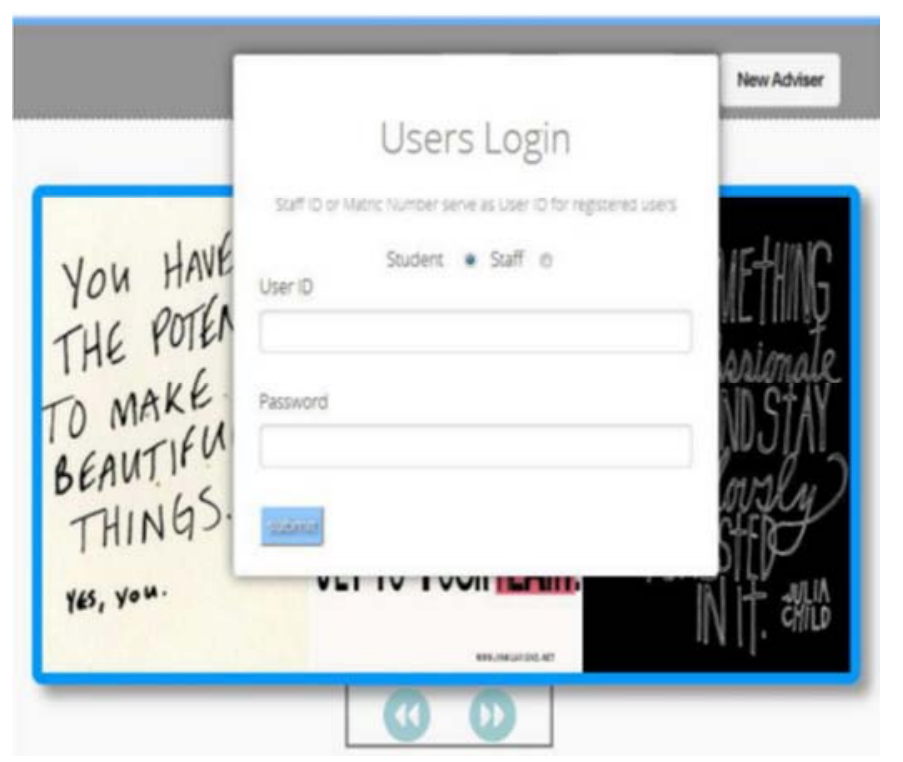

Figure 7. Users' login panel. 


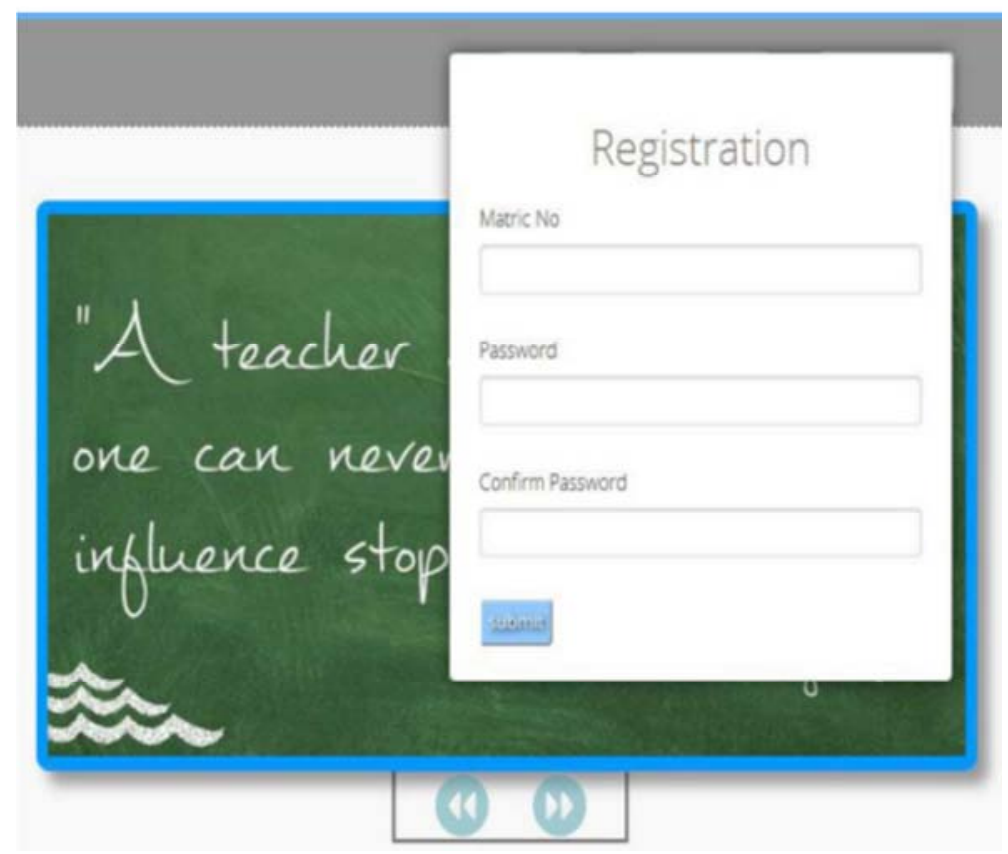

Figure 8. New student registration pop up.

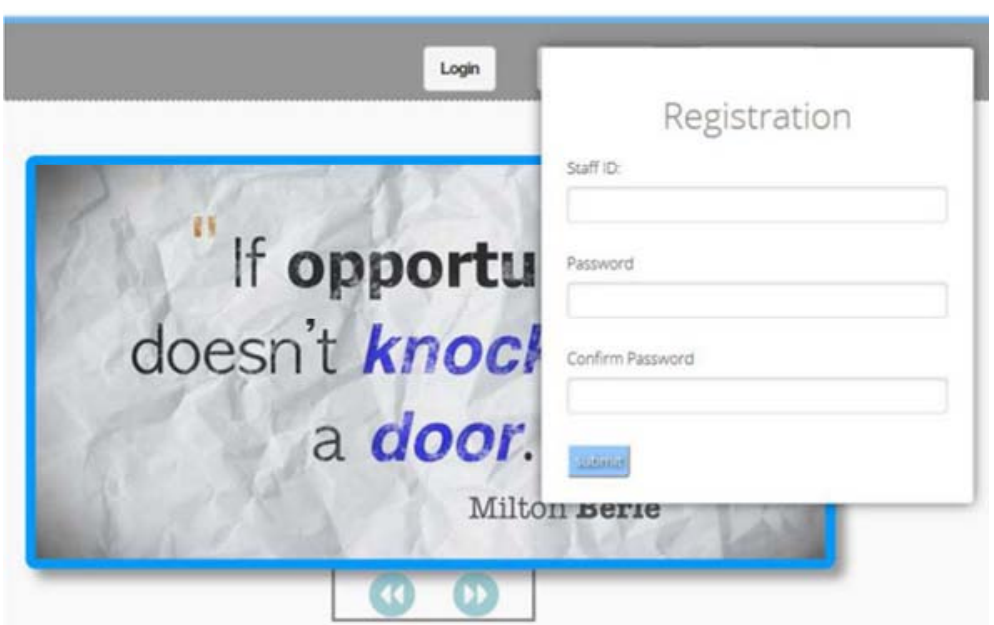

Figure 9. New Adviser registration pop up.

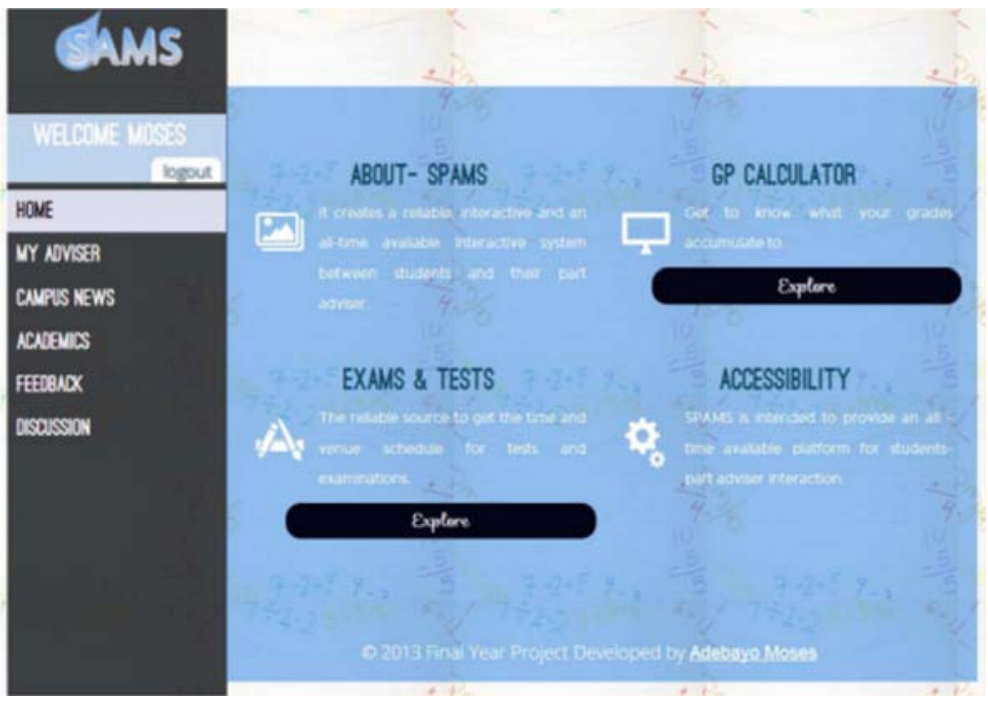

Figure 10. Students' interface login page. 


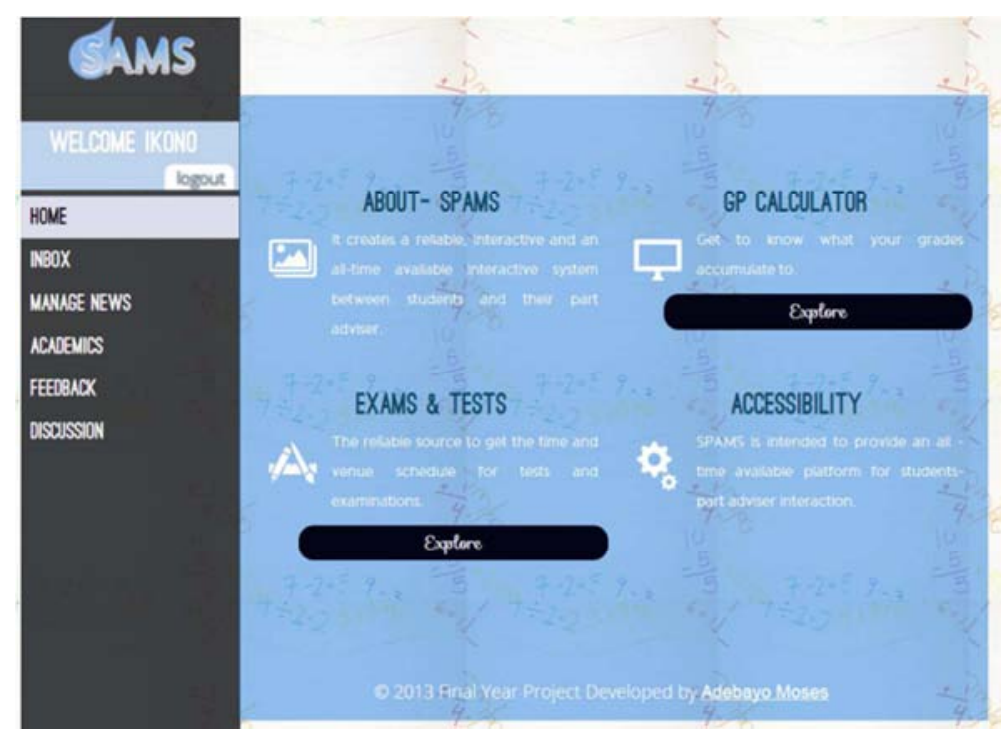

Figure 11. Staffs' interface login page.

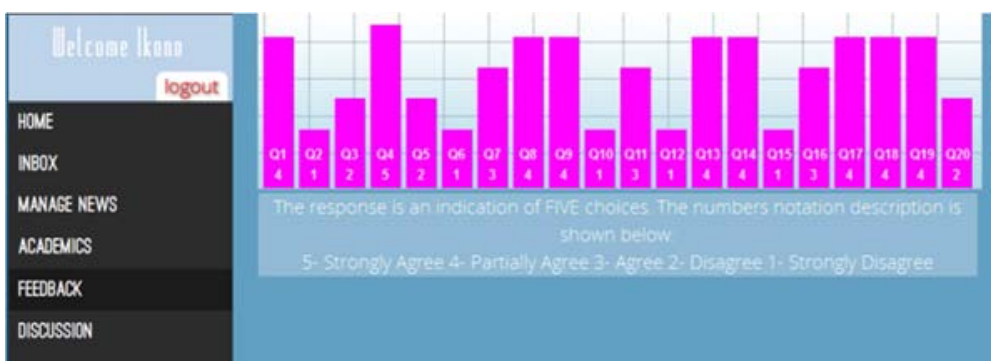

Figure 12. Data visualization of feedbacks.

\subsection{Advisory System}

The part advisers for each level can use the advisory system to interact with their students. The system is flexible in such a way that two advisers can jointly address the problems of students, and the student can have access to timely information. Figure 13 shows the typical view of the in-box of the part advisers. Messages with the "Replied" tag at the bottom shows that they have been attended to by either the current login part adviser or the other part adviser. However, the part adviser can decide to initiate a new conversation with the student. Also, messages with "No Reply" show that none of the part advisers have attended to it.

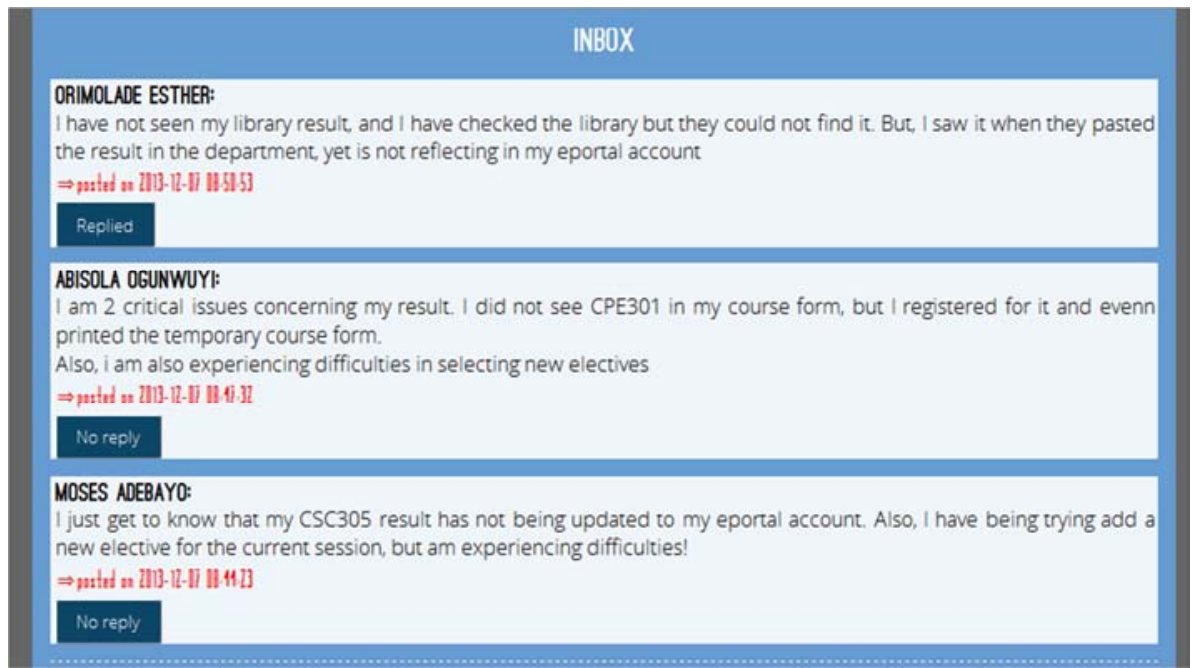

Figure 13. In-box page of staff. 


\subsection{Academic Monitoring}

The system provides a lightweight and fast solution of uploading students result. This is particularly important for the part advisers. The format type of the result to be uploaded should be in "comma separated values (CSV)" format. Microsoft excel spreadsheet can be use in saving file in a CSV format using save as option in Microsoft spreadsheet.

The CSV file should contain three columns which identify the name, score and grade of students. When the result is uploaded, the system automatically generates a new table in the system database and then populates it with the students' name, score and grade. When the result is uploaded, a new table containing the results of all the students is created in the database. The panel for uploading the results is shown in Figure 14. The system use the student login details to reference their result when they want to check their result. This is shown in Figure 15. Again, the result for each is retrieved to them when they decide to check.

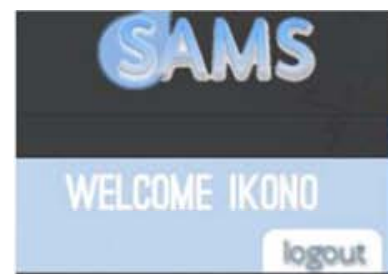

\section{HOME}

INBOX

MANAGE NEWS

\section{ACADEMICS}

FEEDBACK

DISCUSSION

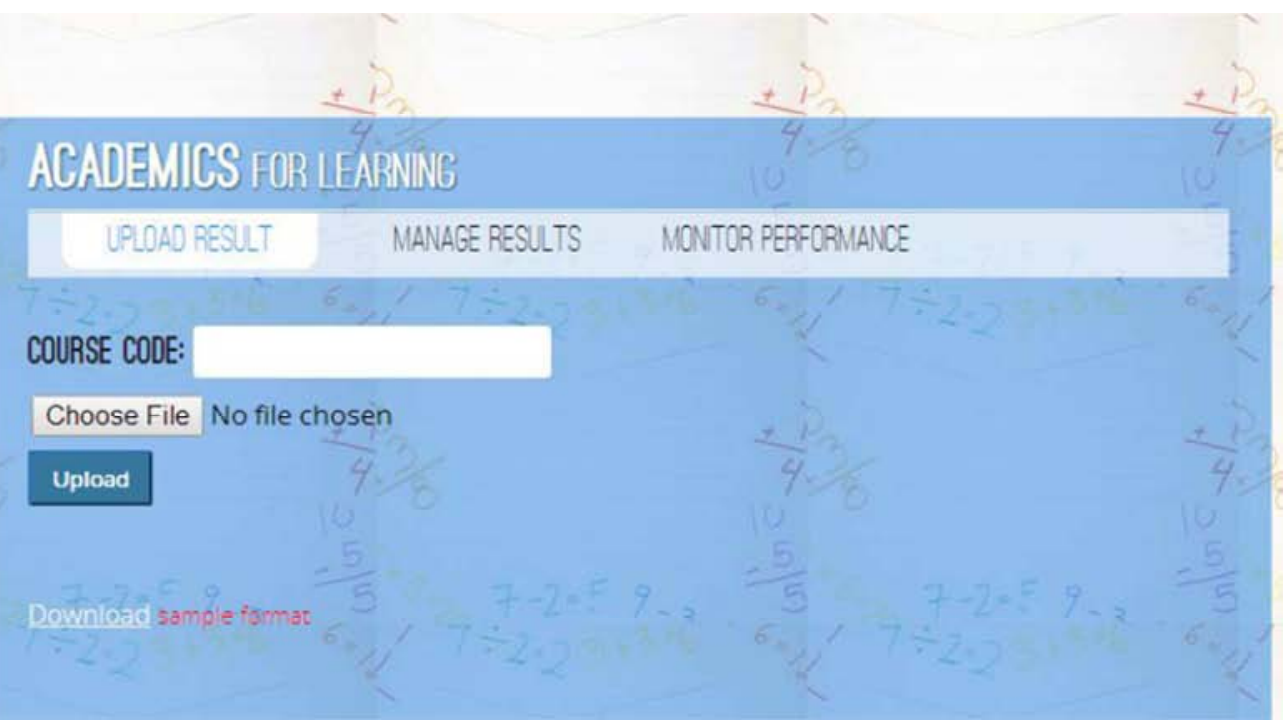

Figure 14. Uploading result panel.
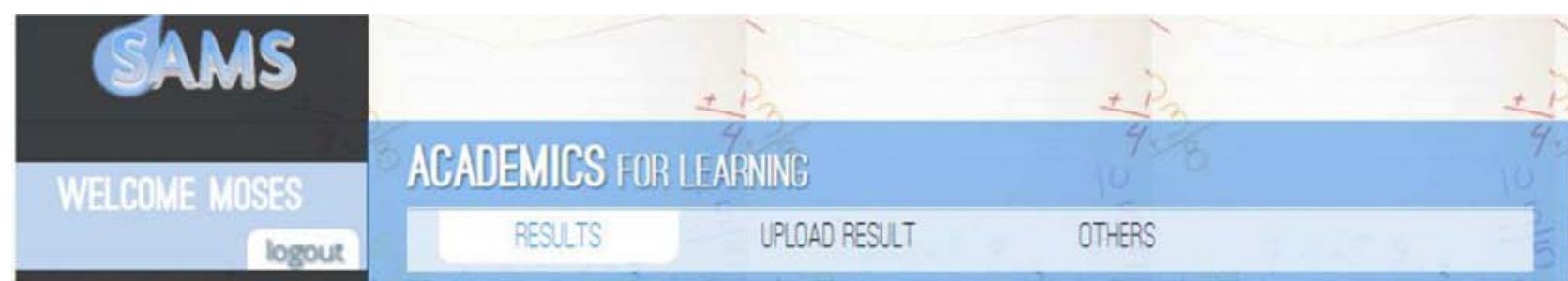

HOME

MY ADVISER

CAMPUS NEWS

ACADEMICS

FEEDBACK

DISCUSSION

UPLOADED RESULTS

COURSE CODE: CSC301 posted on 2013:12:17 13:4733

Your score is 99

Your grade is $\mathrm{A}$

COURSE CODE: CSC2012

check

Figure 15. Students result checker page.

\subsection{System Evaluation}

Each of the components of the system and the system as a whole were evaluated and/or tested to ensure that they functioned properly. This is to ensure that the implementation was done satisfactorily. The different components were tested based on their nature and structure. The tests were carried out by running several case scenarios on them by interacting with the interface. It was done to uncover any bug or loop hole in them. Those that were found were fixed. Examples of the case scenarios are as follows:

a) There are times whereby a particular student will not apply for a particular course, probably due to his/her 
workload being exceeded. The systems check for this possible case and then inform such students the reason for not finding their result. This is shown in Figure 16.

b) The system is also able to catch exceptions in the kind of input that are being sent to the system. A case scenario is when the part adviser wants to create a questionnaire; the system asks for the number of questions that will be in the questionnaire. The system check for the input data type and return an error message if an invalid entry was entered. This is shown in Figure 17.

c) The system permits the part adviser to initiate conversation with their students. The system provides a search bar for the part advisers to check for their students' name. However, in cases whereby the part adviser type in the name of a student that does not belong to the class. The system is able to handle such scenarios by returning the respective error message. This is shown in Figure 18.

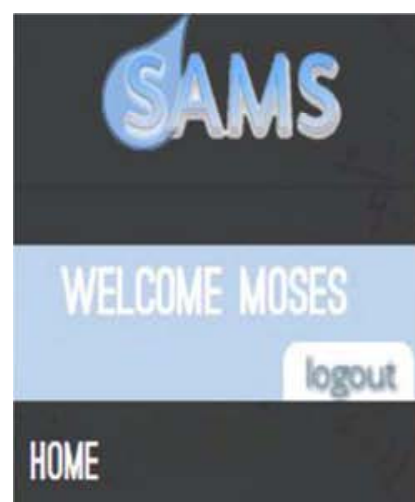

MY ADVISER

CAMPUS NEWS

\section{ACADEMICS}

\section{FEEDBACK}

\section{AGADENIICS FOR LEARING}

UPLDADED RESULITS

\section{COURSE CODE: CSC3O1 oosted on 2013:12:17 13:47:33}

check

COURSE CODE: CSC2012 posted on 2013-12-17 08:21:58

Your record is not found

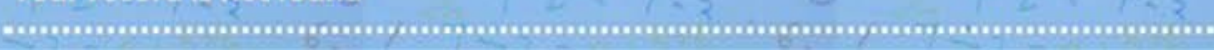

Figure 16. Informing the student of not finding his/her record.
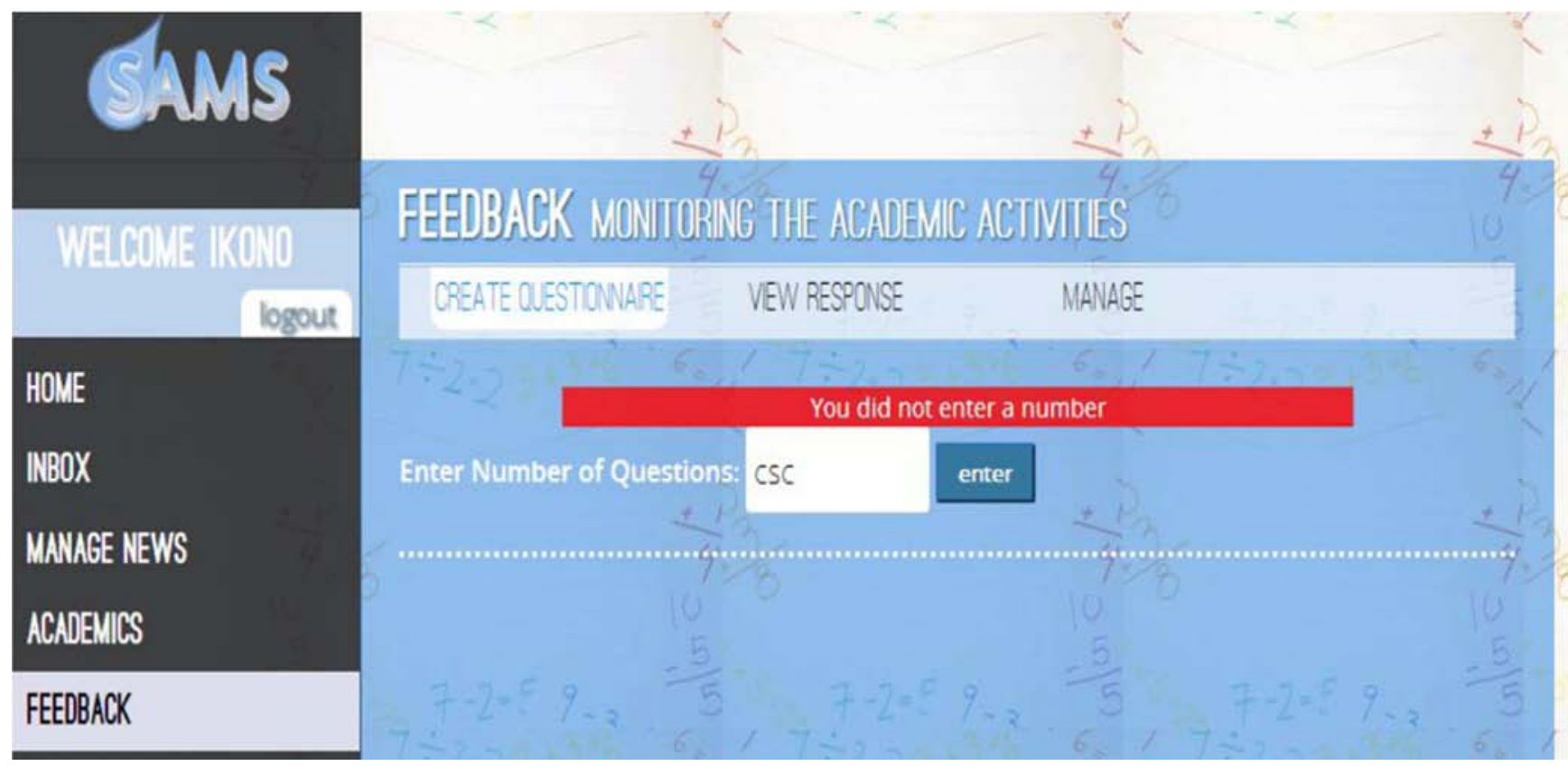

Figure 17. Exception handle I. 


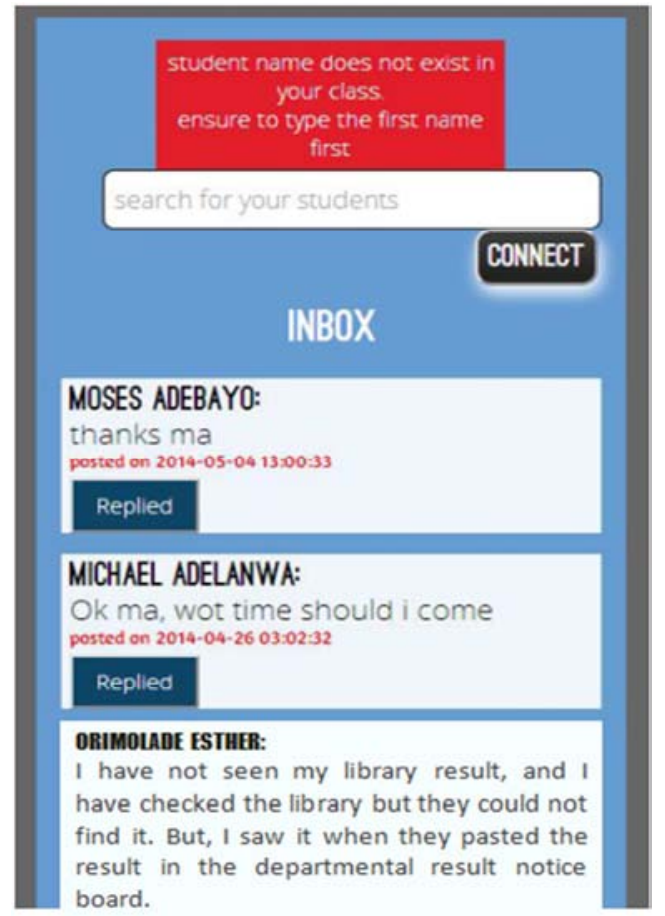

Figure 18. Exception handle II.

\section{Conclusion and Future Work}

It is obvious as opined in the work of Towns et al [16] that digital technologies underpin, accelerate, and enable new, even transformational, research and development in all domains. The educational system as one of such domain is not an exception considering the learning process inherent in it, and the need to manage information as one major success factor when engaging students $[17,18]$. This paper provided an enhanced advisory system for educational purposes through the use of web-based technologies. The system when deployed on the aforementioned departmental website will help students receive better and quality mentoring and monitoring during their academic program. Again, it is believed that the system will open new era of interaction between the part advisers and their students in a meaningful way. It is also expected that the system will help students stay up-to-date on their various courses. It will also help part advisers better manage their students by making use of the platform that serve as an all-time available system.

Going further, the ratio of students to the part adviser assigned to them has affected the role of the part adviser in the academic activities of their students. The project still needs to be improved upon so as to become a viable system. The system functionality can be extended through the use of optimized algorithm to monitor and improve students' academic performance.

\section{References}

[1] Snowman, J. (1997). Educational Psychology: What Do We Teach, What Should We Teach? Educational Psychology, 9, 151-169.
[2] Buckler, B. (1996). A learning process model to achieve continuous improvement and innovation. Learning Organization, 3 (3), 31-39.

[3] Alavi, M., \& Leidner, D. (2001). Knowledge Management Systems: Conceptual Foundations and Research Issues. MIS Quarterly, 25 (1), 107-136.

[4] Currie G, Finn R, \& G., M. (2007). Spanning boundaries in pursuit of effective knowledge sharing within networks in the NHS. 17, 406.

[5] Gupta, B. L., \& Aronson, J. (2000). Knowledge management: practices and challenges ${ }^{\text {ee }}$ Industrial Management \& Data Systems. 100, 17-21.

[6] Gaibreath, J. (2004). Knowledge management technology in education. Information Technology Underused in Education, 28-33.

[7] McLeod, S. A. (2010). Kolb-Learning Style. Retrieved from http://www.simplypsychology.org/learning-kolb.html

[8] Kolb. (1981). Learning styles and disciplinary differences, In A. W. Chickering. San Francisco: Jossey-Bass.

[9] Dakota. (2013). Learnng Process. Retrieved March 12, 2013, from http://www.dakota.fmpdata.net/PsychAI/PrintFiles/DefLrng.pdf

[10] Hayward, L. M., Blackmer, B., \& Raelin, J. (2007). Teaching students a process of reflection: A model for increasing practice-based learning outcomes during cooperative education. Cooperative Education and Internships, 35-47.

[11] Darling-Hammond, L., \& Wentworth, L. (2010). Benchmarking learning systems: Student performance assessment in international context. Stanford Center for Opportunity Policy in Education.

[12] Run-min, F. E. N. G. (2009). Design and Implementation of High Education Student Management System Based on Struts \& Hibernate \& Spring [J]. Computer Engineering, 6, 280-282.

[13] Deniz, D. Z., and Ersan, I. (2002). An Academic Decision Support System Based on Academic Performance Evaluation for Student and Program Assessment. International Journal of Engineering Education, 18 (2), 236-244.

[14] Notley, T. (2008). Online network use in schools: Social and educational opportunities. Youth Studies Australia, 27 (3), 20.

[15] JAIN, R., \& CHLAMTAC, I. (2005). The P* Algorithm for Dynamic calculation of quartiles and histogram without storing observations. (R. G. Sargent, Ed.) Simulation Modelling and statistical computing, 28 (10), 1-10. Retrieved 2013, from http://www.cs.wustl.edu/ jain/papers/ftp/psqr.pdf

[16] Towns, J., Cockerill, T., Dahan, M., Foster, I., Gaither, K., Grimshaw, A., and Roskies, R. (2014). XSEDE: accelerating scientific discovery. In Computing in Science \& Engineering, $16(5), 62-74$

[17] Pearlson, K. E., Saunders, C. S., and Galletta, D. F. (2016). Managing and Using Information Systems, Binder Ready Version: A Strategic Approach. John Wiley \& Sons.

[18] Coates, H., and McCormick, A. C. (2015). Engaging University Students. International Insights from System-Wide Studies. 